\title{
Influencing Factors of Stock Price Crash Risk
}

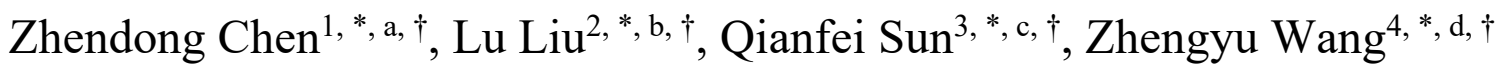 \\ ${ }^{1}$ School of Professional Studies, New York University, New York, 10036, the United States \\ ${ }^{2}$ University of Washington, Seattle, 98105, the United States, \\ ${ }^{3}$ College of Science and Engineering, University of Minnesota, Minneapolis, 55414, the United States \\ ${ }^{4}$ University of Toronto, Toronto, M1C 1A4, Canada \\ ${ }^{*}$ Corresponding author.Email: ${ }^{a} z c 2177 @ n y u . e d u,{ }^{b} l i u l u 98 @ u w . e d u,{ }^{c}$ sun00258@umn.edu, \\ dzhengyu.wang@mail.utoronto.ca \\ ${ }^{\dagger}$ These authors contributed equally.
}

\begin{abstract}
The research on preventing the stock price crash risk is of great significance. Previous literature has examined many influencing factors of crash risk. This paper surveys the burgeoning literature on stock price crash risk. It makes a detailed and comprehensive review of the relevant literature from four parts: (i) the effects of behavioral characteristics of corporate management and shareholders on the stock price crash risk; (ii) the impact of internal corporate decisions on the stock price crash risk; (iii) the influence of external regulatory forces on the stock price crash risk; (iv) the impact of national systems, social habits, as well as the economic policy uncertainty on the stock price crash risk. This literature review is a supplement to the prior literature and is of great significance.
\end{abstract}

Keywords: Stock price crash risk, Information asymmetry, Bad news, Threshold effect

\section{INTRODUCTION}

A slump is when a market maker loses control of a stock's price because of a major adverse event, such as poor liquidity or bad news for the firm.

Because of the market Information asymmetry, investors cannot get the actual information of enterprises in time, which leads to the cognitive bias of investors, and the stock price cannot reflect the negative information of enterprises in time. Over time, the negative news inside the enterprise will accumulate and eventually exceed the critical value that the enterprise can bear to the negative news influence, resulting in the negative news concentrated inside the enterprise and released to the market quickly. As a result, the firm's share price plummeted in a short period, leading to a sharp fall in the share price.

The collapse of stock prices will affect the market value of listed firms, Harm the interests of shareholders and investors, undermine investor confidence in the firm, trigger more selling, affect the stability of the capital market, and even affect the country's real economy. At the same time, the vast financial risks hidden in the stock price crash will not only cause damage to investors' property but also threaten the development of the firm.
When stock prices crash, it can lead to a financial crisis, severe and even bankruptcy.

The significance of studying the risk of a stock-price crash lies in the early detection and prevention of factors that may disrupt healthy market transactions and prevent the occurrence of more serious financial situations, such as the 2008 financial crisis. It is also of great significance to stabilize the stock market, protect investors' interests, and ensure listed companies' healthy and long-term development. Therefore, it has aroused the attention of scholars and regulators, who study the measures to stabilize the stock market, and scholars study the factors that affect the stock price crash. Gender at the firm's board of Directors [1], Age of decision-makers [2], Corporate integrity [3], Corporate social responsibility [4], all have had an impact on the share price crash. This paper makes a comprehensive analysis of the existing literature and summarizes the factors that influence the stock price crash from four aspects: (i) the behavior characteristics of management and shareholders, (ii) the internal decision-making of the firm, (iii) the external supervision, (iv) the national policy. Each aspect summarizes several factors and explains the impact of each factor on the stock price crash risk (positive or negative correlation). 


\section{LITERATURE REVIEW}

\subsection{Behavioral characteristics of corporate management and shareholders on the stock price crash risk}

The Upper Echelons Theory refers to the characteristics of managers that influence their strategy and decision-making choices, thereby impacting the development of the firm. Although the psychological level of management is difficult to analyze, there is still a possibility to analyze and compare from some quantifiable aspects. Based on this theory, there is a connection between the gender, age, religious beliefs, and even early-life disaster experience of management and shareholders and the decisions and strategic choices they make. This paper summarized the possible impact of gender, age, religious beliefs, and early-life disaster experience on the stock price crash risk.

\subsubsection{The effects of gender on stock price crash risk}

Female managers tend to avoid high-risk decisions and choose more conservative strategies. Male managers tend to be more confident and bolder in their decisions than female managers. Therefore, the rewards that match the high risk also be higher. However, female CFOs choose more stable financial decisions and returns. The correlation between $\mathrm{CEO}$ and gender is not significant because CEO is less effective in curbing bad news hoarding than $\mathrm{CFO}$ [1]. But guaranteeing gender diversity at the firm's board of directors can greatly reduce the stock price crash risks. According to research, having three or more female board members tends to make more robust decisions [5]. The gender diversity of the board of directors can reduce risks and make the most reasonable decisions while ensuring benefits.

\subsubsection{The effects of age on stock price crash risk}

The younger the CEO, the more likely the firm is to have negative news and cause stock prices to crash [2]. Even if the firm is steadily increasing its earnings, negative news can easily cause stock prices to crash in the form of interruptions. And, the older you are, the more experienced you are to make decisions and deal with emergencies. Most older people can face high risks and high returns more calmly, and make decisions that balance the two. Therefore, the older the CEO is, the more stable and valuable the firm is. However, the age of executives and CFOs has less of an impact on the risk of stock price plummets than CEOs, because the negative news of these two is difficult to represent the firm directly, and their professional skills are very important. Experience only accounts for a small part [6].

\subsubsection{The effects of religious beliefs on stock price crash risk}

According to the investigation of the Chinese market, religion has made up for the lack of management. Religious beliefs can effectively curb the hoarding of bad news activities by managers [7]. Thus, a firm with a higher degree of overall religious belief has a lower risk of a future stock price crash. However, some religions, such as Taoism, do not influence the stock price crash risk [8].

\subsubsection{The effects of CEO's early disaster experience on stock price crash risk}

CEOs with early-life disaster experience have higher stock price crash risk. Because CEOs who have experienced disasters are more tolerant and accept the risk of bad news hoarding, it is easy to cause stock prices to crash. Besides, when the $\mathrm{CEO}$ has greater equity compensation-based incentives and power over the corporate board to hoard bad news, it accelerates bad news hoarding [9].

Generally speaking, Female management chooses low-risk and low-return strategies, and the stock price crash risk is even smaller. The older the CEO is, the more experience they have to help the firm reduce the stock price crash risk. Religious managers can reduce the accumulation of bad news and reduce risks. Finally, CEOs who have experienced disasters in their early years are more likely to accept bad news hoarding, which often brings greater risks.

\subsection{The influence of firm internal decision-making on stock price crash risk}

It is of great practical importance to study the influence factors of internal decision-making on stock price crash risk, such as the quality of MD \& A disclosure, the level of managerial ownership, corporate integrity, corporate social responsibility information disclosure, etc., to alleviate or avoid information asymmetry. Over the years, more and more attention has been paid to research in this field. Based on abundant literature, the influence of firm internal decision-making on stock price crash risk can be summarized into the following factors.

\subsubsection{The effect of quality of management discussion and analysis (MD\&A) disclosure on stock price crash risk}

Lee and Chae [10] use logistic regression to test whether MD\&A influences crash risk using listed companies in the Korean Stock Exchange (KSE) stock market, which indicates that a firm's high-quality MD\&A implies the management's commitment to communicating with the market, not allowing the 
managers to have incentives to hoard negative news. Thus, the high-quality MD\&A is likely to reduce the stock price crash risk.

\subsubsection{The effect of managerial ownership level on the stock price crash}

RYU and CHAE [11] conduct regression analysis using the data on companies listed on the Korea Composite Stock Price Index (KOSPI) between 20122017 to examine the effect of the managerial ownership level on stock price crash risks, which shows that with the increase of administrative ownership level, the target interests of stockholders and professional managers are more and more consistent, and the possibility of hiding business-related information is reduced, reducing asymmetric information and the stock price crash risk.

\subsubsection{The effect of corporate integrity on stock price crash risk}

Yin and Zhang [3] take 1419 firms listed in Shenzhen Stock Exchange in China as a sample to investigate the impact of corporate integrity on stock price crash risk, showing that in a company with good corporate integrity, the code of conduct and business ethics of managers are high, managers are less likely to make false information and hide bad news, which alleviates information asymmetry and reduces the possibility of stock price crash. Meanwhile, corporate integrity can supplement internal control and the legal system in decreasing stock price crash risks.

\subsubsection{The effect of corporate social responsibility (CSR) disclosure on stock price crash risk}

Dai, Lu, and Qi [4] take Chinese A-share listed companies in 2010-2015 as a sample to examine the relationship between Corporate Social Responsibility (CSR) information disclosure and stock price crash risk using the fixed-effect model. They have shown that mandatory disclosure of CSR information is based on the requirements of the legal system, which is usually standardized and timely. When information disclosure is low, the principal-agent problem is more likely to conceal damaging information, resulting in information asymmetry and increasing stock price crash risk. Furthermore, when information quality rises to a certain level, the possibility of management concealing negative news becomes smaller and smaller, reducing the risk of a stock price crash. It should be an inverted U-shaped relationship between mandatory CSR information disclosure and stock price crash risk.

Semi-mandatory disclosure of CSR information and voluntary disclosure of CSR information is based on social expectations or moral standards, which are greatly affected by subjectivity. Therefore, it is challenging to ensure the authenticity of information disclosure, and there is no inverted U-shaped relationship between semi mandatory and voluntary disclosure and stock price crash risk.

\subsubsection{The threshold effect of leveraged trading on the stock price crash risk}

Peng and $\mathrm{Hu}$ [12] verify the threshold effect of leveraged trading on the stock price crash risk from feedback trading, which indicates that at a low leverage ratio, leveraged trading plays a positive role in mitigating arbitrage restrictions, maintaining market stability, and reducing stock price crash risk. However, when the leverage ratio exceeds a certain threshold, the feedback transaction changes from positive to negative, and the investor sentiment is high and too optimistic, resulting in large fluctuations in the stock price, leading to a sharp decline in the stock price and increasing stock price crash risk.

Corporate internal decision-making is an important aspect affecting the risk of the stock price crash. When making internal decision-making, corporate decision-makers should have risk awareness in this aspect, which can reduce or avoid stock price crash risk.

\subsection{External supervision and stock price crash risk}

The stock price crash risk is also influenced by external supervision forces, including auditors, institutional investors, analysts, and media. The way how each of the above forces poses an effect on stock price crash risk will be discussed below.

\subsubsection{The effect of industry-specialized auditors on stock price crash risk}

According to prior studies, a stock price crash can result from managers' concealing a large amount of bad news [13]. Moreover, the study on the relationship between auditor industry specialization and stock price crash risk revealed that there is a negative relationship between the above two research areas [14]. In general, audit engagements are demanded as monitoring and supervision tools because there are potential conflicts of interest between management and shareholders [15]. It is required that auditors perform the audit services independent of the company being audited, as Watts and Zimmerman [16] presented in their study. Therefore, auditors tend to be good at uncovering bad news within the audited company, which will significantly reduce the possibility of bad news being concealed and accumulated to a great amount, and thus reduce the stock price crash risk. 


\subsubsection{The effects of analysts on stock price crash risk}

$\mathrm{Xu}$, Jiang, Chan, and Yi [17] point out that analyst coverage is positively related to stock price crash risk, and analyst optimism will strengthen this positive relationship. They use China stock market as the database and argue that analysts play an important role in the Chinese stock market due to its nature of opaqueness, the information that analysts provide becomes more valuable to the company. Considering the tendency to conceal negative events unless certain to happen, which is common in the Chinese culture, the possibility of bad news being hidden increases, and thus leads to a stock price crash. Additionally, if analysts are excessively optimistic, whether intentionally or unintentionally, the inclination of hiding bad news will be greater.

\subsubsection{The effects of institutional investors on stock price crash risk}

Variations in institutional investors' behaviors influence the stock price crash risk in different directions. Shleifer and Vishny [18] demonstrate that institutional investors with large shareholdings have the incentive to monitor the performance of management, for example, through collecting information, because they can get a greater return than those with smaller shareholdings. Therefore, institutional investors with large shareholdings may help reduce stock price crash risk.

\subsubsection{The effects of media coverage on stock price crash risk}

In the study conducted by An, Chen, Naiker, and Wang [19], the relationship between media coverage and stock price crash risk is closely examined. As mentioned above, managers withholding bad news will increase the stock price crash risk. They discovered that media coverage influences managers' incentives and capabilities to hoard bad news in terms of the media's informational role, thus influencing stock price crash risk. More specifically, An, Chen, Naiker, and Wang [19] suggest that higher media coverage allows investors to anticipate the firms' future bad news through searching information about firms, industry, market, etc.

\subsection{Macro factors and stock price crash risk}

\subsubsection{The effect of economic policy uncertainty on stock price crash risk}

Dai [20] suggests that in the early stages of the pandemic, the uncertainty caused by COVID-19 has increased and thus decreases stock prices. However, the successive government measures that deal with the pandemic have gradually decreased the economic policy and reduce stock price crash risk. Furthermore, this effect only exists during the pandemic, and it is not significant during regular periods. This illustrates that the stability of economic policies plays a more important role in reducing the extremely negative impact of major crisis events. In the scope of China stock market, economic policy uncertainty is positively and significantly associated with stock price crash risk and the impact of economic policy uncertainty on crash risk is more prominent for SOEs. This effect is more prominent for firms with higher information asymmetry and firms with greater disagreement among investors. However, further study shows that the lagged economic policy uncertainty is negatively associated with stock price crash risk, and therefore the positive impact of economic policy uncertainty on stock crash risk is simultaneous and reverses later.

\subsubsection{The effect of religion on stock price crash risk}

Li [7] suggests that earnings, management, and perk consumption have partial intermediary effects on the risk of religion and stock price crash. The effects of religion on stock price crash risk are exhibited through reducing earnings management and the management perk problem. Additionally, different types of religions have different effects on crash risk in China. For instance, Taoism does not correlate with the crash risk, while some foreign religions, such as Catholicism and Christianity, can significantly reduce stock price crash risk. Furthermore, the effect of religion on stock price crash risk depends on the quality of the governance environment. When the quality of corporate governance and the legal environment is higher, there is a more pronounced negative relationship between religion and crash risk. This indicates that there is a complementary relationship between religion and formal governance mechanisms.

In the scope of the U.S. market, it is noted that firms located in U.S. counties with high levels of religiosity exhibit low levels of future stock price crash risk. The results are consistent with the conjecture that religious social norms can effectively curb managerial bad-news-hoarding activities within firms, thus decreasing future stock price crash risk. Therefore, religiosity is negatively associated with future stock price crash risk [8].

\subsubsection{The effect of culture on stock price crash risk}

Lam [21] states that people from individualistic cultures tend to be more overconfident [22, 23]. Meanwhile, it can be argued that managers from individualistic cultures are more likely to be overconfident. If these managers with individualistic cultures engage in bad news activities, it can lead to higher stock price crash risk. According to the research, it 
is found that individualism has a positive effect on stock price crash risk, which suggests that firms headquartered in individualistic countries are associated with higher stock price crash risk. In addition, this positive effect becomes stronger for firms with high trading volume, overinvestment, and risky investments. Moreover, there is robust evidence supporting the conjecture that individualistic cultures serve as an informal institutional environment that shapes managers' perceptions for hoarding bad news and that these individuals behave opportunistically, triggering stock price crashes. During the global financial crisis, the impact of individualism on crash risk is strengthened. In addition to a significantly positive relationship between individualism and stock price crash risk, it points out that individualism has a larger impact on crash risk in firms with higher foreign institutional ownership, lower managerial discretion over information disclosure, and higher growth rates, and in countries with higher openness and lower information transparency.

\section{CONCLUSION}

In sum, this study researched the effects of different aspects on the stock price crash risk: (i) the effects of behavioral characteristics of corporate management and shareholders on the stock price crash risk; (ii) the impact of internal corporate decisions on the stock price crash risk; (iii) the influence of external regulatory forces on the stock price crash risk; (iv) the impact of national systems, social habits. This research got the implication that some parties can take some approaches to reduce stock price crash risk.

At the internal management level, the gender diversity of the board of directors can reduce stock price crash risk and ensure reasonable benefits. Meanwhile, enacting managers with less early-life disaster experience and elder management teams can reduce the stock price crash risk. From the firm's internal decision-making, the higher quality MD\&A, an increase of administrative ownership level is likely to reduce the stock price crash risk. From a disclosure perspective, good corporate integrity and more transparency CSR can reduce the crash risk.

At the external level, the parties can do so to reduce the stock price crash risk. Auditors who tend to be good at uncovering bad news within the audited company can significantly reduce the possibility of concealed bad news and, therefore, reduce the stock price crash risk. Analysts with less optimism will reduce the stock price crash risk. Institutional investors with large shareholdings may help reduce stock price crash risk. Higher media coverage allows investors to anticipate bad news about firms and reduce the stock price crash risk.

Considering the macro factors, the government can reduce economic policy uncertainty to reduce the stock price crash risk. There is a positive correlation between economic policy uncertainty and stock price crash risk. Religiosity is negatively associated with future stock price crash risk and therefore a high religiosity within the area can reduce the stock price crash risk. Besides, less culture with individualism can have significantly less impact on stock price crash risk.

\section{REFERENCES}

[1] Li, Y., \& Zeng, Y. (2019). The impact of top executive gender on asset prices: Evidence from stock price crash risk. Journal of Corporate Finance, $58,528-550$.

[2] Andreou, P. C., Louca, C., \& Petrou, A. P. (2017). CEO age and stock price crash risk. Review of Finance, 21(3), 1287-1325.

[3] Yin, H., \& Zhang, R. (2020). The Effect of Corporate Integrity on Stock Price Crash Risk. The Journal of Business Economics and Environmental Studies, 10(1), 19-28.

[4] Dai, J., Lu, C., \& Qi, J. (2019). Corporate social responsibility disclosure and stock price crash risk: Evidence from China. Sustainability, 11(2), 448.

[5] Qayyum, A., Rehman, I. U., Shahzad, F., Khan, N., Nawaz, F., Kokkalis, P., \& Sergi, B. S. (2020). Board gender diversity and stock price crash risk: Going beyond tokenism. Borsa Istanbul Review.

[6] Jebran, K., Chen, S., \& Zhang, R. (2020). Board diversity and stock price crash risk. Research in International Business and Finance, 51, 101122.

[7] Li, W., \& Cai, G. (2016). Religion and stock price crash risk: Evidence from China. China Journal of Accounting Research, 9(3), 235-250.

[8] Callen, J. L., \& Fang, X. (2015). Religion and stock price crash risk. Journal of Financial and Quantitative Analysis, 50(1-2), 169-195.

[9] Chen, Y., Fan, Q., Yang, X., \& Zolotoy, L. (2021). CEO early-life disaster experience and stock price crash risk. Journal of Corporate Finance, 68, 101928.

[10] Lee A, Chae S J. The effect of management disclosure and analysis on the stock crash risk: Evidence from Korea[J]. The Journal of Asian Finance, Economics, and Business, 2018, 5(4): 67-72.

[11] RYU, H., \& CHAE, S. J. (2021). The Effect of Managerial Ownership on Stock Price Crash Risk in Distribution and Service Industries. Journal of Distribution Science, 19(1), 27-35. 
[12] Peng, Z., \& Hu, C. (2020). The Threshold Effect of Leveraged Trading on the Stock Price Crash Risk: Evidence from China. Entropy, 22(3), 268.

[13] Jin, L., \& Myers, S. C. (2006). R2 around the world: New theory and new tests. Journal of financial Economics, 79(2), 257-292.

[14] Robin, A. J., \& Zhang, H. (2015). Do industry-specialist auditors influence stock price crash risk?. Auditing: A Journal of Practice \& Theory, 34(3), 47-79.

[15] Watts, R. L. (1977). Corporate financial statements, a product of the market and political processes. Australian journal of management, 2(1), 53-75.

[16] Watts, R., \& Zimmerman, J. (1981). The markets for independence and independent auditors.

[17] Xu, N., Jiang, X., Chan, K. C., \& Yi, Z. (2013). Analyst coverage, optimism, and stock price crash risk: Evidence from China. Pacific-Basin Finance Journal, 25, 217-239.

[18] Shleifer, A., \& Vishny, R. W. (1986). Large shareholders and corporate control. Journal of political economy, 94(3, Part 1), 461-488.

[19] An, Z., Chen, C., Naiker, V., \& Wang, J. (2020). Does media coverage deter firms from withholding bad news? Evidence from stock price crash risk. Journal of Corporate Finance, 64, 101664.

[20] Dai, PF., Xiong, X., Liu, Z. et al. Preventing crash in stock market: The role of economic policy uncertainty during COVID-19. Financ Innov 7, 31 (2021).

[21] Lam Dang, TuDang, T. L., Faff, R., Luong, L. H., \& Nguyen, L. (2017). National Culture and Stock Price Crash Risk. Working Paper. URL: http://www. efmaefm. org/0EFMAMEETINGS/EFMA $\%$ 20ANNUAL $\%$ 20MEETINGS/2017-Athens/papers/EFMA2017_0 376 fullpaper. pdf.

[22] Kagitcibasi, C. (1997). Individualism and collectivism. In J. W, B. Marshall, H. Segall, and C. Kagitcibasi (Eds.), Handbook of Cross-cultural Psychology. Boston: Allyn \& Bacon.

[23] Markus, H. R. and S. Kitayama (1991). Culture and the self: Implications for cognition, emotion, and motivation. Psychological Review 98 (2), 224-253. 